Chapter 15

\title{
Stem Cell Therapy for Parkinson's Disease
}

\author{
Fabin Han \\ Additional information is available at the end of the chapter \\ http://dx.doi.org/10.5772/63340
}

\begin{abstract}
Parkinson's disease (PD) is the second most common neurodegenerative disorder of aging after Alzheimer's disease (AD). Pathologically, it is characterized by a degeneration of dopamine (DA) neurons in substantia nigra of middle brain, which causes the motor symptoms and nonmotor symptoms of PD. The dopamine replacement therapy using levodopa and surgical treatment of deep brain stimulation (DBS) can only improve the symptoms of PD, but cannot stop the disease progression. Because of the selective loss of DA neurons, cell transplantation provides an exciting potential for the treatment of Parkinson's disease. The available cell sources include mesenchymal stem cells (MSCs) from bone marrow, neural stem cells (NSCs) from fetal brain tissues, embryonic stem cells (ESCs) from blastocysts, and induced pluripotent stem cells (iPSCs) reprogrammed from somatic cells transfected with stem cell transcription factors of OCT4, SOX2, KLF4, and c-MYC. Here, we first review the research advance conducted in animal models and patients of PD with these cells, then moving forward to recent development of iPSCs as a future source for the treatment of $\mathrm{PD}$, and highlight the current challenges to make good manufacturing practice (GMP) standard cells suitable for large-scale production to move the cell-based therapy from dish to clinic as soon as possible.
\end{abstract}

Keywords: cell-based therapy, dopamine neuron, embryonic stem cell, induced pluripotent stem cell, neural stem cell, Parkinson's disease

\section{Introduction}

Parkinson's disease (PD) is affecting 1-2\% of the population over the age of 60 years old and $3-$ $5 \%$ of the population above the age of 85 . Clinically, PD patients are characterized with four cardinal symptoms of resting tremors, muscle rigidity, bradykinesia, and postural instability. These motor symptoms appear when $60-80 \%$ of dopamine (DA) neurons in the substantia nigra are degenerated and are used as diagnostic criteria. The nonmotor symptoms have recently 
been highlighted as some of these symptoms including depression, constipation, pain, genitourinary problems, and sleep disorders may precede the motor dysfunction and can be used as early diagnosis and treatment of PD [1].

Because of the decrease of dopamine release in brains of PD patients, either increasing dopamine levels using drugs such as levodopa or reducing the dopamine degradation by dopamine inhibitor carbidopa can play therapeutic effects on PD patients [2]. A surgical treatment called deep brain stimulation (DBS) using electrodes to stimulate to the nucleus subthalamicus is also effective. However, surgical DBS is only suitable for a small portion of the patients and has unclear long-term benefits, while the medications have been found to decline in effectiveness over time and moreover cause the side-effect of dyskinesias (involuntary muscle movements). Recently, great treatment potential has been provided through replacing lost DA neurons using embryonic stem cells (ESCs), induced pluripotent stem cells (iPSCs) reprogrammed from patients' somatic fibroblasts or blood cells, neural stem cells (NSCs), or fully differentiated DA neurons from fetal brain tissue and mesenchymal stem cells (MSCs) sourced from fetuses or adults [3]. A lot of efforts have been done to find suitable cells to improve treatments not just of $\mathrm{PD}$, but of all neurodegenerative diseases.

\section{Etiology and molecular genetics}

The causes of PD can be divided into genetic susceptible genes and environmental toxic environmental substances such as the pesticide rotenone and manganese, which integrate to damage the DA neurons through oxidative stress and mitochondrial impairment to induce PD. The majority of PD cases are sporadic or idiopathic with unknown causes (80-90\%); the remained cases (10-20\%) are familial and can be associated with PD-related genes or linked to a particular monogenic mutation [4-6]. Genetic factors play a minor role in causing typical PD, particularly for the patients having PD after 50 years of age [7]. This suggested that genetic factors are an important factor when the disease begins at or before the age of 50 .

Genetic linkage analysis has great power to identify the disease genes for inherited monogenic diseases. By now more than 200 genes or loci have been characterized for neurological diseases and more than 100 genes or loci were reported for neuromuscular diseases including PD. The public available database for the genes or loci can be found in online catalog of human inherited genes and disorders (http://www.ncbi.nlm.nih.gov/omim/). The first gene for PD is the $\alpha$-synuclein gene that was identified in 1997 [8]. Afterward more genes or loci were found to be responsible for familial PD. The characterized mutated genes for the autosomal dominant form of PD are SNCA and LRRK2 whereas the early-onset autosomal recessive genes for PD are PARK2 (Parkin), PINK1, and PARK7, ATP13A2. Some susceptible genes were also reported to be associated with PD such as Tau, Nurr1, and $\beta$-glucocerebrosidase (GBA). SNCA, which codes for $\alpha$-synuclein, has been particularly well-studied and different point mutations (A53T, A30P, and E46K) in SNCA were found in different families with PD. It seems that the missense mutations of the SNCA gene are rare and the genomic rearrangements including the duplication and triplications of SNCA are more common to induce the aggregation of $\alpha$-synuclein in the dopamine neurons. 
Leucine-rich repeat kinase 2 (LRRK2) is another disease gene for autosomal dominant form of PD. It contains more than 50 exons and codes an 832-amino acid protein, which plays GTPase and kinase functions. Mutations can occur in any exons of LRRK2 gene, but the most common missense mutations are R1441C, Y1699C, G2019A, and I2020T. The G2019S mutation in LRRK2 is worldly prevalent, constituting $4 \%$ of familial PD cases and $1 \%$ of sporadic PD cases. Identification of mutations in the enzymatic GTPase and kinase domains suggests change of these enzymatic activities leads to disease development. Studies have shown that R1441 and Y1699 mutations decrease GTPase activity of LRRK2 whereas G2019S and I2020T mutations increase kinase activity $[9,10]$.

The second locus for PD is PARK2 for parkin gene. Parkin mutations were first reported in the autosomal recessive families of PD. The total genomic size of parkin covered $1.4 \mathrm{Mb}$. It contains 12 exons, and the gene product is a protein with 462 amino acids. The parkin has 30\% homology to ubiquitin in the amino terminal domain and has two RING-finger-like motifs in the carboxyl part of the protein. It was reported that the RING-like structures in parkin have some ubiquitin-ligase activity. By now, more than 100 different mutations of parkin were found in familial and sporadic cases of PD. Most of the Parkin mutations are exonic deletions but missense, nonsense mutations, and genomic rearrangements were also found in PD families.

In addition to the autosomal dominant or recessive genes, some other genes are also reported to be associated with PD. NURR1 is one of the important transcription factors to regulate the development and maturation of the dopamine neurons. We had ever screened 202 familial and sporadic patients with PD and identified one patient has missense mutation of the NURR1 gene. This mutation produced a truncated NURR1 protein that loses the important functional domain to bind the promoter region of the tyrosine hydroxylase (TH), the key kinase to control the synthesis of the dopamine neurotransmitter [11]. GBA is another susceptible gene involved with PD. This gene encodes the lysosomal hydrolase $\beta$-glucocerebrosidase in which mutations are associated with neurodegenerative diseases, such as PD and GD (Gaucher's disease). We have performed a case-control study in a Chinese Cohort with PD and a Chinese control cohort by sequencing all the 12 exons of the GBA gene and found that the PD patients have significantly higher frequency of mutations in the GBA gene. Totally, we found nine reported and three novel GBA mutations in 184 Chinese patients. These known GBA mutations are R163Q, F213I, E326K, S364S, F347L, V375L, L444P, RecNciI, and Q497R and the novel mutations are 5-bp deletion (c.334_338delCAGAA), L264I and L314V. Importantly, we identified the novel 5-bp deletion (CAGAA) that produces a nonfunctional GBA protein of 142 amino acids, which loses major enzymatic function domains of the full GBA protein [12].

\section{Pathological mechanisms}

The mainly pathological mechanism of PD is the degeneration and loss of dopamine (DA) neurons in the substantia nigra of the mesencephalon. These DA neurons project to the basal ganglia (the striatum), which is responsible for motor control and function. The loss of DA neurons is accompanied by Lewy neuritis and Lewy bodies, which cause motor dysfunctions accompanied by an intensification of the disease, including cognitive impairment which 
encompasses hallucinations, dementia, and speech difficulties. The Lewy neurites might hamper the survival and dendritic development of neurons and glial cells through forming insoluble aggregates of $\alpha$-synuclein (coded by SCNA), ubiquitin, and other misfolded proteins [13].

To understand the molecular mechanism and replicate the phenotypic features of PD, different animal models have been studied to explore dopaminergic neurotoxicity mainly using transgenic models of the familial PD-causing genes such as SNCA and LRRK2. The transgenic mice expressing human SNCA showed pathological inclusions in some neurons and glial cells, motor behavior deficits, and loss of dopaminergic neuron terminals in the basal ganglia. Overexpression of SNCA in drosophila leads to age-dependent dopaminergic neuron degeneration. Furthermore, the slowness of movement in LRRK2-G2019S transgenic mouse models was shown to be associated with diminished dopamine release and axonal pathology. These results support a causal role for $\alpha$-synuclein in the development of PD. Some studies also suggest that the cellular toxicity in dopamine neurons may be caused by the soluble cytoplasmic oligomeric $\alpha$-synuclein protein, whereas the large insoluble protein aggregates may represent a cellular defense mechanism in which the cell eventually convert cytotoxicsoluble oligomeric proteins into insoluble inclusion bodies. The $\alpha$-synuclein-containing fibrils in the degenerative dopamine neurons can disturb cell membrane, leading to increased membrane permeability and eventual cell death of affected neural cells [14, 15]. Some studies showed that genetic mutations in PD genes can affect protein trafficking and cellular degradation machinery and eventually lead to development of $\mathrm{PD}$, but the precise role of these mutated genes in disease progression and interaction with need to be further explored. A recent study reported that accumulation of $\alpha$-synuclein reduced lysosomal degradation capacity in human midbrain dopamine neurons. Continuous aggregation of $\alpha$-synuclein in the neural cells disrupted the endoplasmic reticulum-Golgi localization of the key genes such as RAB1a for vesicular transport. Overexpression of RAB1a restored the protein trafficking in endoplasmic reticulum-Golgi pathway and reduced pathological accumulation of $\alpha$-synuclein in neurons. This study proposes that enhancement of lysosomal trafficking probably play beneficial roles in synucleinopathies [16]. Another molecular mechanism of PD is lysosomal dysfunction and the accumulation of glucosylceramide induced by decreased activity of $\beta$ glucocerebrosidase (GBA). Glucosylceramide played roles in stabilizing toxic oligomeric forms of $\alpha$-synuclein and blocking transport of newly synthesized $\beta$-glucocerebrosidase from the endoplasmic reticulum to endocytic compartments, increasing the pathological aggregation of $\alpha$-synuclein in neuronal cells. A recent study revealed that mutation in GBA is a major risk factor for the development of PD and the molecular pathways of pathological accumulation of glucosylceramide, related lipids, and $\alpha$-synuclein will need to be studied for the identification of new therapeutic drugs for PD [12, 17].

\section{Current stem cell sources for cell-based therapy of PD}

Stem cell sources for the treatment of PD have been studied in the past decades. These cells mainly include mesenchymal stem cells from bone marrow and placenta; neural stem cells 
(NSCs) and dopamine neurons from fetal brain tissue; embryonic stem cells (ESCs) of the blastocysts from in vitro fertilization; and induced pluripotent stem cells (iPSCs) reprogrammed from autologous somatic cells by expressing transgenes of OCT4, SOX2, c-MYC, and KLF4.

\subsection{Mesenchymal stem cells}

Mesenchymal stem cells (MSCs) were first reported in 1966, and were described as plasticadherent colony-forming-unit fibroblastic (CFU-F) cells. MSCs are multipotent with potential to differentiate into different cells of mesodermal lineage and transdifferentiate into epithelial, endothelial, and neuronal cells. MSCs can be isolated from various neonatal and adult tissues such as bone marrow, adipose tissue, umbilical cord, cord blood, amnion, placenta, peripheral blood, and dental pulp [18]. Bone marrow-derived MSCs (BM-MSCs) are a potentially promising source of cells for use in regenerative medicine because they are abundantly available, easy to isolate from the patient themselves, an autologous tissue, and there is no ethical dispute over their use. Several studies have shown that BM-MSCs have the potential to regenerate DA neurons for the treatment of PD. Human BM-MSCs also have a protective effect on the progressive loss of DA neurons induced by carbobenzoxy-L-leucyl-Lleucyl-L-leucinal (MG-132) in vitro and in PD rats [19]. After grafted into the striatum, BMMSCs were shown to exert neuroprotective effects against nigrostriatal degeneration and to improve motor function in 6-OHDA lesioned rats [20]. BM-MSCs grown in neuronal differentiation medium have more pronounced effect and improve the motor defects in a 6-OHDA fully lesioned rat PD model. BM-MSCs were induced to have neural morphology and expressed markers of DA neurons, such as tyrosine hydroxylase (TH), and most of the cells survived in striatum, expressed TH and behavioral recovery was observed after the cells were transplanted to a 6-OHDA mouse model. A human MSCs-induced DA subpopulation combined with pharmacologically active microcarriers grafted in a rat PD model also led to protection and repair of the nigrostriatal pathway and behavioral recovery.

The role of genetically modified MSCs for the protection and repair of damaged DA neurons and their therapeutic effects have been studied after implanted into PD models. Park et al. investigated the potential of MSCs genetically engineered with glial derived neurotrophic factor (GDNF) by viral transduction to deliver this potent neurotrophic factor for DA neurons in the brain. They found that MPTP(1-Methyl-4-phenyl-1,2,3,6-tetrahydropyridine) mice that were intravenously injected with GDNF-modified BM-MSCs possessed more TH-IR neurons and fibers and showed more prominent behavioral recovery compared with control mice that were implanted naive BM-MSCs [21]. Barzilay et al. reprogrammed the BM-MSCs toward dopaminergic differentiation through delivery of LMX1a, which was reported to be a key transcriptional factor of dopaminergic differentiation in both embryonic stem cells and developmental animal models. They found that the LMX1a protein was concentrated in the cell nuclei, and the cells with forced expression of LMX1a expressed higher levels of tyrosine hydroxylase, secreted significantly higher level of dopamine comparison with nontransduced cells [22]. Wang et al. tested a cytotherapeutic strategy combining cell transplantation and NTN/Lmx1 $\alpha$ gene therapy to ameliorate disease progression in hemiparkinsonian rhesus. 
They found induced rh-BMSCs exhibited gene/protein expression phenotypes resembling nigral dopaminergic neurons, and these cells survived and retained dopaminergic function following stereotaxic injection into the MPTP-lesioned hemiparkinsonian rhesus [23].

\subsection{Neural stem cells and dopamine neurons from fetal brain tissue}

Neural stem cells (NSCs) were first described as granule cells with a high proliferative activity in the brain cortex and middle brains. These cells have self-renewal and neural differentiation potential and can differentiate into neurons, astrocytes, and oligodendrocytes. In the developing brain, the distribution of NSCs demonstrate regionalization. For instance, only NSCs isolated from the midbrain have been reported to differentiate into A9 mesencephalic DA neurons necessary for treatment of PD patients. Moreover, NSCs can also be isolated from the other regions of fetal brain or from the subventricular zone (SVZ) and hippocampus of the adult mammalian brain, the regions where neurogenesis continues throughout the mammalian's lifespan [24, 25]. Since initial discoveries of NSCs in 1965, research advances in the isolation, expansion, and differentiation of NSCs have been made [26]. After transplantation in the adult rat brain, undifferentiated NSCs show some promise in treatment of PD. Human NSCs transplanted into the rat brain migrate and differentiate to neurons in a site-specific manner. Moreover, in PD rats with depleted host DA levels, engrafted NSCs were sensitive to environmental factors, appearing to differentiate preferentially to DA neurons.

NSCs can also be modified to overexpress the neurotrophic factors, which can increase the survival of the transplanted cells. Cai et al. studied some homeodomain proteins selectively expressed in DA progenitor cells in the ventral midbrain, and found that Lmx1a and Msx1 function as key factors triggering generation of DA neurons. Overexpressing the transcription factor ASCL1 was reported to be able to regain neurogenesis from human neural progenitor cells and to produce larger neurons with more neurites [27]. Animal study showed that forcing expression of Nurr1 promoted the mouse NSCs to differentiate into DA neurons and survive in 6-OHDA-lesioned PD rats. After transplantation of rodent and human fetal brain dopamine neurons to the midbrain of the 6-OHDA-lesioned rats, the cells survived well in the host brains and the motor defects of the PD rats were improved [28, 29]. Based on the results of animal studies, Lindvall et al. started the first clinical trials by transplanting fetal dopaminergic neurons or tissue to PD patients. Since then the clinical assessment protocols have been modified and significant effects were found by detecting behavioral and histological improvement [30, 31]. Moreover, younger PD patients showed more significant improvements, implying that the treatment efficiency may be limited in certain subpopulations. Generally, long-term graft survival was poor and did not convincingly justify the use of three to five human embryos per procedure [32]. In general, variable functional outcome has been showed from the clinical trials, but solid improvements need to be determined by clinical and imaging evaluations in the future $[33,34]$. Transplantation of NSCs in PD patients also showed some side-effects. Olanow et al. reported that $56 \%$ of patients transplanted with fetal midbrain tissue developed persistent dyskinesia after overnight withdrawal of dopaminergic medication [35], which was much more than Freed et al.'s result of $15 \%$ of patients showing dyskinesias [31]. Its exact prevalence may be argued, while the recurrence of dyskinesia 
following neural transplantation has been well-proved. Some evidence showed that grafts containing serotonin neurons were easier to have this detrimental effect, therefore dyskinesias symptom may be alleviated by ensuring a homogeneous cell population in transplanted tissue [36].

Long-term follow-up results were shown in three individual clinical studies. One study found transplanted fetal midbrain DA neurons survived up to 14 years without pathology [37], whereas others found that $\alpha$-synuclein-positive Lewy bodies in eventual spread to the transplanted DA neurons in PD patients [38, 39]. These findings suggest that PD can be an ongoing process with pathological changes. The controversy may be the reason of the difference between environmentally and genetically caused PD-a case of PD caused by environmental factors might be cured by the infusion of healthy cells, whereas a case of PD, which has been caused by genetic mutations would be an ongoing process. In general, DA neuron engraftment cannot be stated as a universally permanent treatment for PD; follow-up implantations may be further required for optimal effectiveness. Like all other allogeneic treatments, there is also a risk of graft rejection which must be repressed in the study [40]. Overall, the clinical trials with NSCs of fetal brains showed the survival of the transplanted cells and some improvements of symptoms in PD patients, whereas some results are over in dispute because of the diversities or limited cases of the PD patients [34]. Table 1 summarized some of the clinical trials with fetal brain-derived NSCs or dopamine neurons.

\begin{tabular}{|c|c|c|c|c|}
\hline $\begin{array}{l}\text { No. of patients } \\
\text { transplanted with } \\
\text { NSC }\end{array}$ & $\begin{array}{l}\text { Observation } \\
\text { time }\end{array}$ & $\begin{array}{l}\text { Symptom } \\
\text { improvement } \\
0 / 0\end{array}$ & $\begin{array}{l}\text { Side effect of } \\
\text { dyskinesia }\end{array}$ & $\begin{array}{l}\text { References and } \\
\text { publication year }\end{array}$ \\
\hline 1 & 12 months & $1 / 1$ & No & [41] \\
\hline 6 & $10-72$ months & $4 / 6$ & No & [42] \\
\hline 5 & 18-24 months & $2 / 5$ & No & [43] \\
\hline $20 / 40$ & 3 years & $17 / 20$ & No & [31] \\
\hline $23 / 34$ & 24 months & $6 / 23$ & Yes & [35] \\
\hline 2 & 8 years & $2 / 2$ & Yes & {$[44]$} \\
\hline 5 & 9-14 years & Not available & Not available & [37] \\
\hline 1 & 14 years & $1 / 1$ & Yes & [39] \\
\hline 2 & $11-16$ years & Not available & Not available & [38] \\
\hline 33 & $2-4$ years & $45 \%$ & Not available & {$[45]$} \\
\hline 3 & $13-16$ years & Yes & Not available & {$[46]$} \\
\hline 2 & 18 and 15 years & $2 / 2$ & Not available & [47] \\
\hline
\end{tabular}

Note: 23/34 indicates that 23 of 34 cases are in the group transplanted with NSCs and the other cases are in the control group.

Table 1. The clinical trials in PD patients transplanted with fetal brain-derived neural stem cells. 
To further address the clinical therapeutic effects of the transplanted NSCs, and to provide new guidelines for clinical trials of fetal brain-derived cell therapy for PD treatment, a new, multicenter and collaborative study of European Union (TRANSEURO) was formed in 2010. These need careful selection of patients: early in the course of their disease (disease duration 2-10 years); aged 30-68 at the time of inclusion, showing a good response to levodopa; systematically evaluation of cell preparation, and location of transplantation; immunosuppression after transplantation and follow-up time; numbers of patients and clinical assessment standards. The new clinical trial for more than 100 patients suffered with PD has completed in this study, and results are in the analysis [48, 49].

\subsection{Human embryonic stem cells (hESCs)-derived neural stem cells and dopamine neurons}

Embryonic stem cells (ESCs) are self-renewing, pluripotent, and isolated from the inner cell mass cells of the preimplantation blastocysts. ESC can be differentiated into any kind of tissue cells including neural stem cells (NSCs), neurons, and DA neurons under special microenvironment. The differentiated neural stem cells, or fully differentiated neurons and dopamine neurons from mouse embryonic stem cell have been proved to have effects for PD neuroprotection [50].

Originally, human embryonic stem cells (hESCs) were isolated through culturing inner cell mass cells using mouse embryonic fibroblasts (MEFs) as feeder cells [51]. Since then, many groups have developed methods to direct the hESC differentiation to the neural stem cells and neurons, in particular dopamine neurons for the treatment of PD. Cooper et al. employed sonic hedgehog (SHH) and FGF8a as patterning factors in DA neuron induction [52]. The differentiation of hESCs to mesencephalic dopamine neurons was promoted by the application of specific patterning molecules that regulate mesencephalon development [53] or by applying growth factors SHH and FGF8a in a specific sequence [54]. Early exposure of FGF8a and SHH instructs early precursors to adopt a region identity which promotes DA neuron differentiation from mesencephalic neuroepithelial cells. These hESC-derived dopamine neurons were able to improve the motor deficiency of PD rat models, suggesting that grafted hESC-derived dopamine neurons played a role in vivo. The efficiency of DA production from pluripotent stem cells was greatly improved by Chamber et al. using a developed protocol through inhibiting SMAD signaling using Noggin and SB431542, with enhancing survival of mesencephalic DA neurons from hESCs [55]. They found that addition of Noggin and SB431542 for inhibiting SMAD signaling is sufficient to induce complete neural conversion of more than $80 \%$ of hESCs under adherent culture conditions. Fasano et al. found complimentary results, showing that neurons in development did not form toward anterior regionalization, but may be shifted toward a midbrain-like identity after FGF8 or Wnt1 treatment [56]. The same group developed a floor-plate-based protocol for generating hESCs-derived DA neurons in differentiation medium containing activators of sonic hedgehog $(\mathrm{SHH})$ and canonical WNT signaling in vitro, further improved complete conversion of hESCs to the dopamine neurons and decreased the teratoma formation in vivo. They found that these DA neurons efficiently grew for several months in vitro and restored the amphetamine-induced rotation behaviors and improvements in tests of akinesia and forelimb use after transplanted to Parkinsonian 
monkeys and 6-OHDA-lesioned rats [57]. Sanchez-Danes et al. reported that using lentiviral expression of LMX1A, the key DA neuron-regulating gene, in hESCs to obtain more than $60 \%$ ventral mesencephalic DA neurons of the A9 subtype of all neurons differentiated from LMX1A-modified hESC [58]. Grealish et al. studied the functional properties of hESC-derived DA neurons in vivo by implanting hESC-derived mesencephalic dopamine neurons and fetal brain DA neurons into the brains of PD rats. They found that grafted hESC-DA neurons survived, projected long neural branches and played functions to improve the locomotive deficits of PD rats as similar as fetal brain DA neurons by MRI and PET imaging analysis, which provided further preclinical basis of hESC-derived dopamine neurons for PD patients' treatment [59].

To dissolve the major concerns for clinical use with stromal cells as feeder cells for culturing hESCs, some groups developed the implementation of factors which substitute for feeder cells. For example, Schulz et al. used a serum-free suspension system for generating the neurons, which are clinically applicable use [60]. Vazin et al. succeeded in substituting growth factors SDF-1, PTN, IGF2, and EFNB1 for the PA6 stromal cells, resulting in the induction of differentiating hESCs directly to TH-positive DA neurons without requiring this initial induction step [61]. During differentiating hESCs to NSCs, Swistowski et al. reported that growth factors SHH and FGF8 substitute for PA6 stromal cells for generating DA cells after an initial induction step. They endeavored a culture protocol applicable to the clinic and following to the standards of good manufacturing protocol (GMP). In their culture process, serum is not involved, but they found cells could be stored at each of the intermediate stages in their four-step process (propagation of ESC $\rightarrow$ generation of neural stem cells (NSC) $\rightarrow$ induction of dopaminergic precursors $\rightarrow$ maturation of dopaminergic neurons) without loss of functional ability, which is an important discovery that allowing cells to be transplanted at an appropriate time point in neural development [62].

Though many studies demonstrated hESCs can be differentiated to DA neurons efficiently in vitro and showed solid functional results to restore the motor defects in PD animal models including mice, rats, and nonhuman primates, clinical trials have not been performed for treating the PD patients because of the immune-rejection and ethical issues.

\subsection{Induced pluripotent stem cells (iPSCs)-derived neural stem cells or dopamine neurons}

Previous studies showed an undifferentiated state of cells could be reprogrammed from differentiated somatic cells using the somatic cell nuclear transfer (SCNT). SCNT technology is available to make the cloned lambs and cows. However, no studies were described generating patient-specific cells using this SCNT technique [63, 64]. The successful induction of mouse iPSCs from mouse embryonic and adult fibroblasts were first demonstrated in Yamanaka lab in 2006 by introducing four transcription factors of Oct3/4, Sox2, c-Myc, and Klf4 [65]. Soon afterward, human iPSCs and patient-specific iPSCs with different diseases including PD were also generated from several labs by introducing the human orthologs of these four transcription factors (OCT4, SOX2, c-MYC, and KLF4) or OCT4, SOX2, NANOG, and LIN28 $[66,67]$. The implication of Oct3/4 and Sox 2 was shown to play an essential role in the propagation of undifferentiated ESCs in culture. The roles of Klf4 and c-Myc were equally 
undecided. Later studies described that the only genes indispensable in generating iPSCs were Oct3/4 and Sox 2 but not Klf4 and c-Myc [68]. Similar to ESCs, iPSCs are self-renew indefinitely and pluripotent. However, iPSCs overcome the problems associated with BM-MSCs, fetal NSCs and hESCs, as they reprogram from the already-differentiated somatic cells of an organism back to their embryonic-like pluripotent state. iPSCs generated from patients will have wide applications for exploring the molecular mechanisms and cell-based therapy of neurodegenerative diseases such as PD $[69,70]$.

In clinical applications, one of the major advantages of iPSCs over BM-MSCs, fetal NSCs, and hESCs is that iPSCs can be generated from the cells of the individual being treated. As the cultured cells will be autologous, this key trait of iPSCs theoretically enhances their integration into the brain tissues of PD patients and minimizes the risk of rejection. Furthermore, the ethical problems of using aborted fetuses as a cell source are avoided. Once reprogrammed into iPSC state from the mature cells, the iPSCs can be systematically exposed to specific factors that promote their differentiation into a specific lineage (such as NSCs or DA neurons) [71]. Until now, a ton of work has been done to improve the generation, differentiation, and potential clinical applications of iPSCs, especially with great efforts made to bring these therapeutic cells to meet GMP (good manufacturing practice) standards, to translate them to the clinic for treatment of neurodegenerative diseases like PD. iPSCs have also been used in other fields such as diseases model to study the molecular mechanisms of the disease and as drug screening and discovery.

To determine the clinical potential of iPSCs-derived cells, the therapeutic effects of mouse iPSCs were analyzed after transplanting them into the rat brains. Wernig et al. reported that grafted iPSCs matured into midbrain-like dopamine neurons, resulting in behavioral improvements in rat PD models [72].

It was found that DA neurons from the iPSCs with LRRK2 mutation (G2019S) were sensitive to oxidative stress and had $\alpha$-synuclein aggregation and more expression of key oxidative stress-response genes. The phenotypic neurodegeneration of the differentiated DA neurons could be rescued by correction of LRRK2 G2019S mutation in iPSCs, supporting LRRK2 mutation playing an important role in the pathogenesis of PD [73]. The virus-free PD-iPS cellsderived DA neurons were transplanted to the 6-OHDA-lesioned rats and it was found that these DA neurons survived and provided functional improvements in PD rats by alleviating motor defects induced by apomorphine [74]. Recently, our lab made efforts to generate of iPS cells by retrovirus-mediated expression of OCT4, SOX2, c-MYC, and KLF4 from skin fibroblasts of PD patients and control individuals, and studied the differentiation of iPSCs to NSCs and DA neurons, and then transplanted the iPSCs-derived NSCs into the striatums of the 6OHDA-induced PD rats. iPSCs carrying the transgenes can also be differentiated to the NSCs and be fully differentiated to neurons and DA neurons in vitro and in vivo. The grafted iPS cells-derived NSCs significantly improved the rotational asymmetry of PD rats [4]. Further work are needed to improve the differentiation efficiency of neurons and DA neurons by incorporating growth factors and iPSCs together for transplantation, or elevating the dose of immune-suppressive agents to lower the immune-rejection against the human-derived cells, or renewing the cell culture protocols. 
Much work has been done toward improving the efficiency of iPSCs generation in absence of c-Myc. Stadtfeld et al. reprogrammed mouse liver cells into iPSCs using nonintegrating, replication-incompetent adenoviruses carrying the classic four transcription factors [75]. Okita et al. developed an approach that repeated transfection of plasmids containing the appropriate genes (one containing the complementary DNAs of Oct3/4, SOx2, and Klf4; the other, c$\mathrm{Myc}$ ) into embryonic fibroblasts could generate iPSCs [76]. Yu et al. developed a further protocol to iPSC generation by using nonintegrating episomal vectors, which allows the derivation of iPSCs free of vector and transgene sequences completely [77]. The direct protein transduction system free of DNA vector was also proposed to generate iPSCs to remove potential risks in association with chromosomal integrations and mutations [78].

This claim is verified by the follow-up study through comparing the cellular properties of human iPSCs (hiPSC) generated by chromosome integrating with nonintegrating methods. They found consistent differences in cellular and differentiation properties between hiPSCs from nonintegrating and integrating reprogramming factors. According to their results, protein-based reprogramming of cells into hiPSCs resulted in cells showed no obvious exogenous reprogramming gene expression, therefore behaved most similar to hESCs [79].

Many efforts have been done to achieve clinical-grade DA neurons with a stable phenotype, the A9 subtype DA neurons. From both human ES/iPS cells, a strategy for efficient differentiation and sorting DA neurons has been developed by Isacson et al. From iPSC-differentiated neural cells, the NCAM (+)/CD29 (low)-enriched ventral mesencephalic DA neurons were sorted. The sorted neurons were positive for EN1/TH and FOXA2/TH and had elevated expression levels of GIRK2, FOXA2, PITX3, LMX1A, NURR1, TH, and EN1 which indicated that the sorted neural cells are DA neurons. These iPSC-derived DA neurons were able to restore behavior activity of PD rats after transplantation. The sorted cells transplanted to the PD rats were integrated into the brain tissue. Their results provided molecular basis for the safety and feasibility of iPSC-derived cell therapies [80].

The similarity and differences between iPSCs and ESC is another issue about iPSCs. Many studies succeeded in generating both human iPSCs and mouse iPSCs identical to ESCs developmentally and epigenetically by improving end points for the reprogramming process [81]. Other groups have also made modifications to reduce the mutagenic potential of the lentiviruses and retroviruses By using non-integrating methods or omitting the KLF4 or cMYC. For instance, Muller et al. found that substituting Nanog and Lin28 for Klf4 and cMyc [67] was one way to reduce this risk. The reactivation of the c-Myc retrovirus particularly promotes the risk of mutations, because of tumorigenicity [82]. However, the efficiency of iPSC formation was far lower after eliminations of c-Myc from the protocol. This suggests that the role of c-Myc is not being necessary in the establishing pluripotency itself but to accelerate proliferation or otherwise enhance the speed of events establishing pluripotency [83]. Although the generated iPSCs in morphology, growth properties, and differentiation into different germ layers were very similar to ESCs, differences between iPSCs and ESCs were detected, which may be the reason by using different iPSC lines [84]. Recently at the molecular levels, the similarity and difference between iPSCs and hESCs were studied. In one study, Koyanagi-Aoi et al found that only two hiPSC lines had different gene expression and DNA 
methylation through analyzing 49 hiPSC lines and 10 hESC lines. And they found that only seven hiPSC lines formed some undifferentiated cells by comparing neural differentiation in vitro between 40 hiPSC lines and $10 \mathrm{hESC}$ lines. This study showed that hiPSCs are very similar to hESCs [85].

The important point is that such protocols need to meet a xeno-free, scalable system for the clinic. A suspension culture system was created for the neural differentiation of hESCs and hiPSCs [86]. Such systems allowed long-term cell culture while keeping appropriate marker expression, normal karyotype, and pluripotency. To decrease the effects of transgenes on iPSCs functions, several labs developed protocols to use two or three factors to generate iPSCs. Using single factor of OCT4 in combination of small molecules of VPA, TGF- $\beta$ inhibitor (616452), CHIR 99021, iPSCs can be reprogrammed from mouse adult and embryonic fibroblasts [68]. Omitting the OCT4, the naive iPSCs derived from rhesus monkey fibroblasts can be obtained with only small molecules, which provided a valuable cell source for further use in disease modeling and preclinical study [87]. Though iPSCs bring great potentials to the cellbased PD therapy, much work is needed for the researchers to find other convenient method to obtain DA neurons as the complicated procedures for generation, characterization, and differentiation to the DA neurons. Directly reprograming the fibroblasts of PD patients to DA neurons is one of the other approaches. Using different combinations of transcription factors such as Nurr1 (Nr4a2), Mash1 (Ascl1), Sox2, Ngn2, Lmx1a, and Pitx3, DA neurons were directly reprogrammed from the fibroblasts $[88,89]$. Since the lentiviral vectors were used to express the genes related in most direct reprogramming methods for development of DA neurons, this can cause the safety concerns for use of the directly reprogrammed DA neurons in PD patients. However, the research advance will overcome these issues and finally bring these cells to clinical trials for PD.

\section{Future aspects and challenges for clinical application of iPSCs}

The NSCs and DA neurons from fetal brain and hESCs are not suitable for wide clinical use because of their immune-rejections and ethical issues. The availability of iPSCs has great potential for autologous cell-based therapy of PD. The treatment of eye-disorders using iPSCs for clinical trial has been initiated in Japan. However, several aspects of iPSCs are further needed to be resolved for clinical use. These include genetic and epigenetic abnormalities, low yields of DA neurons, and the safety of iPSC-derived cells.

\subsection{Low yield}

Low yield of fully reprogrammed cells is by no means an inherent property of iPSC generation and there will continue to be yield improvements in the future. Low yield is a potential problem, addition of VPA and other chemicals increased the original yields of $0.05 \%$ [90]. iPSCs can theoretically be sourced from anywhere on the adult human, such as stomach cells, liver cells, and human hair cells, with varying yields across experiments [75]. In fact, Aasen et al. generated keratinocyte-derived iPSCs using cells from adult human hairs with a 100-fold 
increase in efficiency compared to human fibroblast reprogramming, and found these iPSCs were indistinguishable from ESCs [91]. In any case, with the goal of optimizing methods for maximum cell yield of iPS cells, avenues must include comparisons between method efficiencies in the future.

\subsection{Genetic and epigenetic abnormalities}

It is unclear whether iPSCs cells toward a cell fate related to their donor source or otherwise maintaining a reprogramming signature after differentiation [92]. For the generation of clinical applicable iPS cells, the lentivirus or retrovirus-mediated reprogramming methods should be replaced by nonintegrating vectors to express the reprogramming genes or combine with small molecules [93]. Some iPSCs from PD patients may also have gene mutations such as chromosomal structure variation, point mutation, gene deletions, and duplications $[12,94]$. It is not suitable to use the cells derived from iPSCs with genetic mutations for direct transplantation as the functions of cells are affected by the genetic mutations. Many reports developed protocols to correct the mutation in PD patient-derived iPSCs. Reinhardt et al. showed that iPSCs with LRRK2 G2019S mutation was corrected and the LRRK2 correction produced phenotype rescue in differentiated neurons [73]. Soldner et al. reported that the iPSCs with SNCA mutation (A53T) was repaired using zinc-finger nuclease (ZFN)-mediated nuclease approach and genetic repair of the A53T mutation in the patient-derived iPSCs did not affect the differentiation ability to dopaminergic neurons. The correctly repaired patient-derived iPSC lines were confirmed through PCR genotyping and sequencing analysis [95].

\subsection{Safety and purity}

It is required that the residues of undifferentiated iPSCs should be less than $1 \%$ to avoid the teratoma formation after transplantation, in the aim to obtain iPSC-derived NSCs or DA neurons for transplantation. FACS or other noninvasive magnetic selections were used for developing the approaches to sort the iPSC-derived cells. Moreover, the cell culture in feederfree conditions are needed to avoid the contamination of animal sources. Currently, murinederived feeder cells are widely used to maintain hESCs and hiPSCs. In addition, these feeder cells are normally cultured in culture medium including fetal bovine serum (FBS). This would enhance the possibility to cause the allogenic cell contamination of the iPSC-derived cells. Nakagawa et al. developed a new feeder-free system to culture the hESCs and iPSCs in StemFit ${ }^{\mathrm{TM}}$ medium, which made a big step to make clinically applicable GMP-standard cells [96].

\section{Conclusion: moving forward to the clinic}

Cell-based therapy holds clinical potential for the treatment of many neurodegenerative disorders including PD. The use of BM-MSCs, fetal NSCs, and ESCs is facing with safety and ethical concerns. However, recently great advance is making in developing iPSC-derived cells for PD. Animal studies using injection iPSCs and their derivatives into animal models have 
shown promise in treatment of disorders such as PD. However in clinical trials for PD, iPSCs have not been used until their limitations are overcome. Therefore, a relevant therapeutic progenitor or mature cell type may be identified and grafted in such treatments; in the case of PD, the options are of course iPSC-derived DA neurons and iPSC-derived NSCs.

\section{Acknowledgements}

This work was supported by National Natural Science Foundation of China (NSFC 81571241) and Program of high-educated Foreign Scholars, Shandong Province, China (201309116SDWZ). The author also thanks Jing Duan and Qingfa Chen for their technical and editing the manuscript.

\section{Author details}

Fabin $\operatorname{Han}^{*}$

Address all correspondence to: fhan2013@126.com

The Institute for Tissue Engineering and Regenerative Medicine, Liaocheng University/The Liaocheng People's Hospital, Shandong, China

\section{References}

[1] Berg, D., R.B. Postuma, B. Bloem, P. Chan, B. Dubois, T. Gasser, C.G. Goetz, G.M. Halliday, J. Hardy, A.E. Lang, I. Litvan, K. Marek, J. Obeso, W. Oertel, C.W. Olanow, W. Poewe, M. Stern, and G. Deuschl. Time to redefine PD? Introductory statement of the MDS Task Force on the definition of Parkinson's disease. Mov Disord. 2014; 29(4): 454-62.

[2] Olanow, C.W., R.L. Watts, and W.C. Koller. An algorithm (decision tree) for the management of Parkinson's disease (2001): treatment guidelines. Neurology. 2001; 56(11 Suppl 5): S1-S88.

[3] Takahashi, K., K. Tanabe, M. Ohnuki, M. Narita, T. Ichisaka, K. Tomoda, and S. Yamanaka. Induction of pluripotent stem cells from adult human fibroblasts by defined factors. Cell. 2007; 131(5): 861-72.

[4] Han, F., W. Wang, B. Chen, C. Chen, S. Li, X. Lu, J. Duan, Y. Zhang, Y.A. Zhang, W. Guo, and G. Li. Human induced pluripotent stem cell-derived neurons improve motor asymmetry in a 6-hydroxydopamine-induced rat model of Parkinson's disease. Cytotherapy. 2015; 17(5): 665-79. 
[5] Lesage, S. and A. Brice. Parkinson's disease: from monogenic forms to genetic susceptibility factors. Hum Mol Genet. 2009; 18(R1): R48-59.

[6] Chen, M.L., C.H. Lin, M.J. Lee, and R.M. Wu. BST1 rs11724635 interacts with environmental factors to increase the risk of Parkinson's disease in a Taiwanese population. Parkinsonism Relat Disord. 2014; 20(3): 280-3.

[7] Tanner, C.M., R. Ottman, S.M. Goldman, J. Ellenberg, P. Chan, R. Mayeux, and J.W. Langston. Parkinson disease in twins: an etiologic study. JAMA. 1999; 281(4): 341-6.

[8] Polymeropoulos, M.H., C. Lavedan, E. Leroy, S.E. Ide, A. Dehejia, A. Dutra, B. Pike, H. Root, J. Rubenstein, R. Boyer, E.S. Stenroos, S. Chandrasekharappa, A. Athanassiadou, T. Papapetropoulos, W.G. Johnson, A.M. Lazzarini, R.C. Duvoisin, G. Di Iorio, L.I. Golbe, and R.L. Nussbaum. Mutation in the alpha-synuclein gene identified in families with Parkinson's disease. Science. 1997; 276(5321): 2045-7.

[9] Grimes, D.A., L. Racacho, F. Han, M. Panisset, and D.E. Bulman. LRRK2 screening in a Canadian Parkinson's disease cohort. Can J Neurol Sci. 2007; 34(3): 336-8.

[10] Martin, I., J.W. Kim, V.L. Dawson, and T.M. Dawson. LRRK2 pathobiology in Parkinson's disease. J Neurochem. 2014; 131(5): 554-65.

[11] Grimes, D.A., F. Han, M. Panisset, L. Racacho, F. Xiao, R. Zou, K. Westaff, and D.E. Bulman. Translated mutation in the Nurr1 gene as a cause for Parkinson's disease. Mov Disord. 2006; 21(7): 906-9.

[12] Yu, Z., T. Wang, J. Xu, W. Wang, G. Wang, C. Chen, L. Zheng, L. Pan, D. Gong, X. Li, H. Qu, F. Li, B. Zhang, W. Le, and F. Han. Mutations in the glucocerebrosidase gene are responsible for Chinese patients with Parkinson's disease. J Hum Genet. 2015; 60(2): 85-90.

[13] Dawson, T.M., H.S. Ko, and V.L. Dawson. Genetic animal models of Parkinson's disease. Neuron. 2010; 66(5): 646-61.

[14] Gonzalez-Horta, A. The Interaction of Alpha-synuclein with Membranes and its Implication in Parkinson's Disease: a literature review. Nat Prod Commun. 2015; 10(10): 1775-8.

[15] Fares, M.B., N. Ait-Bouziad, I. Dikiy, M.K. Mbefo, A. Jovicic, A. Kiely, J.L. Holton, S.J. Lee, A.D. Gitler, D. Eliezer, and H.A. Lashuel. The novel Parkinson's disease linked mutation G51D attenuates in vitro aggregation and membrane binding of alphasynuclein, and enhances its secretion and nuclear localization in cells. Hum Mol Genet. 2014; 23(17): 4491-509.

[16] Mazzulli, J.R., F. Zunke, O. Isacson, L. Studer, and D. Krainc. alpha-Synuclein-induced lysosomal dysfunction occurs through disruptions in protein trafficking in human midbrain synucleinopathy models. Proc Natl Acad Sci U S A. 2016; 113(7): 19316. 
[17] Blanz, J. and P. Saftig. Parkinson's disease: acid-glucocerebrosidase activity and alphasynuclein clearance. J Neurochem. 2016.

[18] Hass, R., C. Kasper, S. Bohm, and R. Jacobs. Different populations and sources of human mesenchymal stem cells (MSC): a comparison of adult and neonatal tissue-derived MSC. Cell Commun Signal. 2011; 9: 12.

[19] Park, H.J., P.H. Lee, O.Y. Bang, G. Lee, and Y.H. Ahn. Mesenchymal stem cells therapy exerts neuroprotection in a progressive animal model of Parkinson's disease. J Neurochem. 2008; 107(1): 141-51.

[20] Blandini, F., L. Cova, M.T. Armentero, E. Zennaro, G. Levandis, P. Bossolasco, C. Calzarossa, M. Mellone, B. Giuseppe, G.L. Deliliers, E. Polli, G. Nappi, and V. Silani. Transplantation of undifferentiated human mesenchymal stem cells protects against 6hydroxydopamine neurotoxicity in the rat. Cell Transplant. 2010; 19(2): 203-17.

[21] Park, K.W., M.A. Eglitis, and M.M. Mouradian. Protection of nigral neurons by GDNFengineered marrow cell transplantation. Neurosci Res. 2001; 40(4): 315-23.

[22] Barzilay, R., T. Ben-Zur, S. Bulvik, E. Melamed, and D. Offen. Lentiviral delivery of LMX1a enhances dopaminergic phenotype in differentiated human bone marrow mesenchymal stem cells. Stem Cells Dev. 2009; 18(4): 591-601.

[23] Wang, W.P., Z.L. He, S.Y. Lu, M. Yan, Y. Zhou, T.H. Xie, N. Yin, W.J. Wang, D.H. Tang, H.J. Li, and M.S. Sun. Dopaminergic neuron-like cells derived from bone marrow mesenchymal stem cells by Lmx1alpha and neurturin overexpression for autologous cytotherapy in hemiparkinsonian rhesus monkeys. Curr Stem Cell Res Ther. 2015; 10(2): 109-20.

[24] Eriksson, P.S., E. Perfilieva, T. Bjork-Eriksson, A.M. Alborn, C. Nordborg, D.A. Peterson, and F.H. Gage. Neurogenesis in the adult human hippocampus. Nat Med. 1998; 4(11): 1313-7.

[25] Taupin, P. and F.H. Gage. Adult neurogenesis and neural stem cells of the central nervous system in mammals. J Neurosci Res. 2002; 69(6): 745-9.

[26] Kallur, T., V. Darsalia, O. Lindvall, and Z. Kokaia. Human fetal cortical and striatal neural stem cells generate region-specific neurons in vitro and differentiate extensively to neurons after intrastriatal transplantation in neonatal rats. J Neurosci Res. 2006; 84(8): 1630-44.

[27] Kim, H.J., E. McMillan, F. Han, and C.N. Svendsen. Regionally specified human neural progenitor cells derived from the mesencephalon and forebrain undergo increased neurogenesis following overexpression of ASCL1. Stem cells. 2009; 27(2): 390-8.

[28] Studer, L., V. Tabar, and R.D. McKay. Transplantation of expanded mesencephalic precursors leads to recovery in parkinsonian rats. Nat Neurosci. 1998; 1(4): 290-5. 
[29] Monni, E., C. Cusulin, M. Cavallaro, O. Lindvall, and Z. Kokaia. Human fetal striatum-derived neural stem (NS) cells differentiate to mature neurons in vitro and in vivo. Curr Stem Cell Res Ther. 2014; 9(4): 338-46.

[30] Lindvall, O., G. Sawle, H. Widner, J.C. Rothwell, A. Bjorklund, D. Brooks, P. Brundin, R. Frackowiak, C.D. Marsden, P. Odin, et al. Evidence for long-term survival and function of dopaminergic grafts in progressive Parkinson's disease. Ann Neurol. 1994; 35(2): 172-80.

[31] Freed, C.R., P.E. Greene, R.E. Breeze, W.Y. Tsai, W. DuMouchel, R. Kao, S. Dillon, H. Winfield, S. Culver, J.Q. Trojanowski, D. Eidelberg, and S. Fahn. Transplantation of embryonic dopamine neurons for severe Parkinson's disease. N Engl J Med. 2001; 344(10): 710-9.

[32] Hagell, P. and P. Brundin. Cell survival and clinical outcome following intrastriatal transplantation in Parkinson disease. J Neuropathol Exp Neurol. 2001; 60(8): 741-52.

[33] Lindvall, O. and A. Bjorklund. Cell therapy in Parkinson's disease. NeuroRx. 2004; 1(4): 382-93.

[34] Barker, R.A., J. Barrett, S.L. Mason, and A. Bjorklund. Fetal dopaminergic transplantation trials and the future of neural grafting in Parkinson's disease. Lancet Neurol. 2013; 12(1): 84-91.

[35] Olanow, C.W., C.G. Goetz, J.H. Kordower, A.J. Stoessl, V. Sossi, M.F. Brin, K.M. Shannon, G.M. Nauert, D.P. Perl, J. Godbold, and T.B. Freeman. A double-blind controlled trial of bilateral fetal nigral transplantation in Parkinson's disease. Ann Neurol. 2003; 54(3): 403-14.

[36] Politis, M., K. Wu, C. Loane, N.P. Quinn, D.J. Brooks, S. Rehncrona, A. Bjorklund, O. Lindvall, and P. Piccini. Serotonergic neurons mediate dyskinesia side effects in Parkinson's patients with neural transplants. Sci Transl Med. 2010; 2(38): 38 ra46.

[37] Mendez, I., A. Viñuela, A. Astradsson, K. Mukhida, P. Hallett, H. Robertson, T. Tierney, R. Holness, A. Dagher, and J.Q. Trojanowski. Dopamine neurons implanted into people with Parkinson's disease survive without pathology for 14 years. Nat Med. 2008; 14(5): 507.

[38] Li, J.Y., E. Englund, J.L. Holton, D. Soulet, P. Hagell, A.J. Lees, T. Lashley, N.P. Quinn, S. Rehncrona, A. Bjorklund, H. Widner, T. Revesz, O. Lindvall, and P. Brundin. Lewy bodies in grafted neurons in subjects with Parkinson's disease suggest host-to-graft disease propagation. Nat Med. 2008; 14(5): 501-3.

[39] Kordower, J.H., Y. Chu, R.A. Hauser, T.B. Freeman, and C.W. Olanow. Lewy body-like pathology in long-term embryonic nigral transplants in Parkinson's disease. Nat Med. 2008; 14(5): 504-6.

[40] Michel-Monigadon, D., V. Nerriere-Daguin, X. Leveque, M. Plat, E. Venturi, P. Brachet, P. Naveilhan, and I. Neveu. Minocycline promotes long-term survival of neuronal 
transplant in the brain by inhibiting late microglial activation and T-cell recruitment. Transplantation. 2010; 89(7): 816-23.

[41] Lindvall, O., P. Brundin, H. Widner, S. Rehncrona, B. Gustavii, R. Frackowiak, K.L. Leenders, G. Sawle, J.C. Rothwell, C.D. Marsden, and et al. Grafts of fetal dopamine neurons survive and improve motor function in Parkinson's disease. Science. 1990; 247(4942): 574-7.

[42] Wenning, G.K., P. Odin, P. Morrish, S. Rehncrona, H. Widner, P. Brundin, J.C. Rothwell, R. Brown, B. Gustavii, P. Hagell, M. Jahanshahi, G. Sawle, A. Bjorklund, D.J. Brooks, C.D. Marsden, N.P. Quinn, and O. Lindvall. Short- and long-term survival and function of unilateral intrastriatal dopaminergic grafts in Parkinson's disease. Ann Neurol. 1997; 42(1): 95-107.

[43] Hagell, P., A. Schrag, P. Piccini, M. Jahanshahi, R. Brown, S. Rehncrona, H. Widner, P. Brundin, J.C. Rothwell, P. Odin, G.K. Wenning, P. Morrish, B. Gustavii, A. Bjorklund, D.J. Brooks, C.D. Marsden, N.P. Quinn, and O. Lindvall. Sequential bilateral transplantation in Parkinson's disease: effects of the second graft. Brain. 1999; $122(\mathrm{Pt} \mathrm{6})$ : 1121-32.

[44] Pogarell, O., W. Koch, F.J. Gildehaus, A. Kupsch, O. Lindvall, W.H. Oertel, and K. Tatsch. Long-term assessment of striatal dopamine transporters in Parkinsonian patients with intrastriatal embryonic mesencephalic grafts. Eur J Nucl Med Mol Imaging. 2006; 33(4): 407-11.

[45] Ma, Y., C. Tang, T. Chaly, P. Greene, R. Breeze, S. Fahn, C. Freed, V. Dhawan, and D. Eidelberg. Dopamine cell implantation in Parkinson's disease: long-term clinical and (18)F-FDOPA PET outcomes. J Nucl Med. 2010; 51(1): 7-15.

[46] Politis, M., K. Wu, C. Loane, N.P. Quinn, D.J. Brooks, W.H. Oertel, A. Bjorklund, O. Lindvall, and P. Piccini. Serotonin neuron loss and nonmotor symptoms continue in Parkinson's patients treated with dopamine grafts. Sci Transl Med. 2012; 4(128): 128ra41.

[47] Kefalopoulou, Z., M. Politis, P. Piccini, N. Mencacci, K. Bhatia, M. Jahanshahi, H. Widner, S. Rehncrona, P. Brundin, A. Bjorklund, O. Lindvall, P. Limousin, N. Quinn, and T. Foltynie. Long-term clinical outcome of fetal cell transplantation for Parkinson disease: two case reports. JAMA Neurol. 2014; 71(1): 83-7.

[48] Moore, S.F., N.V. Guzman, S.L. Mason, C.H. Williams-Gray, and R.A. Barker. Which patients with Parkinson's disease participate in clinical trials? One centre's experiences with a new cell based therapy trial (TRANSEURO). J Parkinsons Dis. 2014; 4(4): 671-6.

[49] Evans, J.R., S.L. Mason, and R.A. Barker. Current status of clinical trials of neural transplantation in Parkinson's disease. Prog Brain Res. 2012; 200: 169-98. 
[50] Liu, T.W., Z.G. Ma, Y. Zhou, and J.X. Xie. Transplantation of mouse CGR8 embryonic stem cells producing GDNF and TH protects against 6-hydroxydopamine neurotoxicity in the rat. Int J Biochem Cell Biol. 2013; 45(7): 1265-73.

[51] Thomson, J.A., J. Itskovitz-Eldor, S.S. Shapiro, M.A. Waknitz, J.J. Swiergiel, V.S. Marshall, and J.M. Jones. Embryonic stem cell lines derived from human blastocysts. Science. 1998; 282(5391): 1145-1147.

[52] Cooper, O., G. Hargus, M. Deleidi, A. Blak, T. Osborn, E. Marlow, K. Lee, A. Levy, E. Perez-Torres, A. Yow, and O. Isacson. Differentiation of human ES and Parkinson's disease iPS cells into ventral midbrain dopaminergic neurons requires a high activity form of SHH, FGF8a and specific regionalization by retinoic acid. Mol Cell Neurosci. 2010; 45(3): 258-66.

[53] Zeng, X., J. Cai, J. Chen, Y. Luo, Z.B. You, E. Fotter, Y. Wang, B. Harvey, T. Miura, C. Backman, G.J. Chen, M.S. Rao, and W.J. Freed. Dopaminergic differentiation of human embryonic stem cells. Stem Cells. 2004; 22(6): 925-40.

[54] Yan, Y., D. Yang, E.D. Zarnowska, Z. Du, B. Werbel, C. Valliere, R.A. Pearce, J.A. Thomson, and S.C. Zhang. Directed differentiation of dopaminergic neuronal subtypes from human embryonic stem cells. Stem Cells. 2005; 23(6): 781-90.

[55] Chambers, S.M., C.A. Fasano, E.P. Papapetrou, M. Tomishima, M. Sadelain, and L. Studer. Highly efficient neural conversion of human ES and iPS cells by dual inhibition of SMAD signaling. Nat. Biotechnol. 2009; 27(3): 275-80.

[56] Fasano, C.A., S.M. Chambers, G. Lee, M.J. Tomishima, and L. Studer. Efficient derivation of functional floor plate tissue from human embryonic stem cells. Cell Stem Cell. 2010; 6(4): 336-47.

[57] Kriks, S., J.W. Shim, J. Piao, Y.M. Ganat, D.R. Wakeman, Z. Xie, L. Carrillo-Reid, G. Auyeung, C. Antonacci, A. Buch, L. Yang, M.F. Beal, D.J. Surmeier, J.H. Kordower, V. Tabar, and L. Studer. Dopamine neurons derived from human ES cells efficiently engraft in animal models of Parkinson's disease. Nature. 2011; 480(7378): 547-51.

[58] Sanchez-Danes, A., A. Consiglio, Y. Richaud, I. Rodriguez-Piza, B. Dehay, M. Edel, J. Bove, M. Memo, M. Vila, A. Raya, and J.C. Izpisua Belmonte. Efficient generation of A9 midbrain dopaminergic neurons by lentiviral delivery of LMX1A in human embryonic stem cells and induced pluripotent stem cells. Hum Gene Ther. 2012; 23(1): $56-69$.

[59] Grealish, S., E. Diguet, A. Kirkeby, B. Mattsson, A. Heuer, Y. Bramoulle, N. Van Camp, A.L. Perrier, P. Hantraye, A. Bjorklund, and M. Parmar. Human ESC-derived dopamine neurons show similar preclinical efficacy and potency to fetal neurons when grafted in a rat model of Parkinson's disease. Cell Stem Cell. 2014; 15(5): 653-65.

[60] Schulz, T.C., S.A. Noggle, G.M. Palmarini, D.A. Weiler, I.G. Lyons, K.A. Pensa, A.C. Meedeniya, B.P. Davidson, N.A. Lambert, and B.G. Condie. Differentiation of human 
embryonic stem cells to dopaminergic neurons in serum-free suspension culture. Stem Cells. 2004; 22(7): 1218-38.

[61] Vazin, T., K.G. Becker, J. Chen, C.E. Spivak, C.R. Lupica, Y. Zhang, L. Worden, and W.J. Freed. A novel combination of factors, termed SPIE, which promotes dopaminergic neuron differentiation from human embryonic stem cells. PLoS One. 2009; 4(8): e6606.

[62] Swistowski, A., J. Peng, Y. Han, A.M. Swistowska, M.S. Rao, and X. Zeng. Xeno-free defined conditions for culture of human embryonic stem cells, neural stem cells and dopaminergic neurons derived from them. PLoS One. 2009; 4(7): e6233.

[63] Wilmut, I., A.E. Schnieke, J. McWhir, A.J. Kind, and K.H. Campbell. Viable offspring derived from fetal and adult mammalian cells. Nature. 1997; 385(6619): 810-3.

[64] Jullien, J., V. Pasque, R.P. Halley-Stott, K. Miyamoto, and J.B. Gurdon. Mechanisms of nuclear reprogramming by eggs and oocytes: a deterministic process? Nat Rev Mol Cell Biol. 2011; 12(7): 453-9.

[65] Takahashi, K. and S. Yamanaka. Induction of pluripotent stem cells from mouse embryonic and adult fibroblast cultures by defined factors. Cell. 2006; 126(4): 663-76.

[66] Park, I.H., R. Zhao, J.A. West, A. Yabuuchi, H. Huo, T.A. Ince, P.H. Lerou, M.W. Lensch, and G.Q. Daley. Reprogramming of human somatic cells to pluripotency with defined factors. Nature. 2008; 451(7175): 141-6.

[67] Yu, J., M.A. Vodyanik, K. Smuga-Otto, J. Antosiewicz-Bourget, J.L. Frane, S. Tian, J. Nie, G.A. Jonsdottir, V. Ruotti, R. Stewart, Slukvin, II, and J.A. Thomson. Induced pluripotent stem cell lines derived from human somatic cells. Science. 2007; 318(5858): 1917-20.

[68] Li, Y., Q. Zhang, X. Yin, W. Yang, Y. Du, P. Hou, J. Ge, C. Liu, W. Zhang, X. Zhang, Y. Wu, H. Li, K. Liu, C. Wu, Z. Song, Y. Zhao, Y. Shi, and H. Deng. Generation of iPSCs from mouse fibroblasts with a single gene, Oct4, and small molecules. Cell Res. 2011; 21(1): 196-204.

[69] Isobe, K., Z. Cheng, N. Nishio, T. Suganya, Y. Tanaka, and S. Ito. Reprint of "iPSCs, aging and age-related diseases". N Biotechnol. 2015; 32(1): 169-79.

[70] Han, F. The Applications of the Induced Pluripotent Stem Cells in Studying the Neurodegenerative Diseases. Chin J Cell Biol. 2012; 34(5): 13.

[71] Kiskinis, E. and K. Eggan. Progress toward the clinical application of patient-specific pluripotent stem cells. J Clin Invest. 2010; 120(1): 51-9.

[72] Wernig, M., J.-P. Zhao, J. Pruszak, E. Hedlund, D. Fu, F. Soldner, V. Broccoli, M. Constantine-Paton, O. Isacson, and R. Jaenisch. Neurons derived from reprogrammed fibroblasts functionally integrate into the fetal brain and improve symptoms of rats with Parkinson's disease. Proc Natl Acad Sci. 2008; 105(15): 5856-61.

[73] Reinhardt, P., B. Schmid, L.F. Burbulla, D.C. Schondorf, L. Wagner, M. Glatza, S. Hoing, G. Hargus, S.A. Heck, A. Dhingra, G. Wu, S. Muller, K. Brockmann, T. Kluba, M. Maisel, 
R. Kruger, D. Berg, Y. Tsytsyura, C.S. Thiel, O.E. Psathaki, J. Klingauf, T. Kuhlmann, M. Klewin, H. Muller, T. Gasser, H.R. Scholer, and J. Sterneckert. Genetic correction of a LRRK2 mutation in human iPSCs links parkinsonian neurodegeneration to ERKdependent changes in gene expression. Cell Stem Cell. 2013; 12(3): 354-67.

[74] Hargus, G., O. Cooper, M. Deleidi, A. Levy, K. Lee, E. Marlow, A. Yow, F. Soldner, D. Hockemeyer, P.J. Hallett, T. Osborn, R. Jaenisch, and O. Isacson. Differentiated Parkinson patient-derived induced pluripotent stem cells grow in the adult rodent brain and reduce motor asymmetry in Parkinsonian rats. Proc Natl Acad Sci U S A. 2010; 107(36): 15921-6.

[75] Stadtfeld, M., M. Nagaya, J. Utikal, G. Weir, and K. Hochedlinger. Induced pluripotent stem cells generated without viral integration. Science. 2008; 322(5903): 945-9.

[76] Okita, K., M. Nakagawa, H. Hyenjong, T. Ichisaka, and S. Yamanaka. Generation of mouse induced pluripotent stem cells without viral vectors. Science. 2008; 322(5903): 949-53.

[77] Yu, J., K. Hu, K. Smuga-Otto, S. Tian, R. Stewart, Slukvin, II, and J.A. Thomson. Human induced pluripotent stem cells free of vector and transgene sequences. Science. 2009; 324(5928): 797-801.

[78] Kim, D., C.H. Kim, J.I. Moon, Y.G. Chung, M.Y. Chang, B.S. Han, S. Ko, E. Yang, K.Y. Cha, R. Lanza, and K.S. Kim. Generation of human induced pluripotent stem cells by direct delivery of reprogramming proteins. Cell Stem Cell. 2009; 4(6): 472-6.

[79] Rhee, Y.H., J.Y. Ko, M.Y. Chang, S.H. Yi, D. Kim, C.H. Kim, J.W. Shim, A.Y. Jo, B.W. Kim, H. Lee, S.H. Lee, W. Suh, C.H. Park, H.C. Koh, Y.S. Lee, R. Lanza, and K.S. Kim. Protein-based human iPS cells efficiently generate functional dopamine neurons and can treat a rat model of Parkinson disease. J Clin Invest. 2011; 121(6): 2326-35.

[80] Sundberg, M., H. Bogetofte, T. Lawson, J. Jansson, G. Smith, A. Astradsson, M. Moore, T. Osborn, O. Cooper, and R. Spealman. Improved cell therapy protocols for Parkinson's disease based on differentiation efficiency and safety of hESCcy ion -, and nonhuman primate iPSC-derived dopaminergic neurons. Stem Cells. 2013; 31(8): 1548-62.

[81] Maherali, N., R. Sridharan, W. Xie, J. Utikal, S. Eminli, K. Arnold, M. Stadtfeld, R. Yachechko, J. Tchieu, R. Jaenisch, K. Plath, and K. Hochedlinger. Directly reprogrammed fibroblasts show global epigenetic remodeling and widespread tissue contribution. Cell Stem Cell. 2007; 1(1): 55-70.

[82] Okita, K., T. Ichisaka, and S. Yamanaka. Generation of germline-competent induced pluripotent stem cells. Nature. 2007; 448(7151): 313-7.

[83] Muller, L.U., G.Q. Daley, and D.A. Williams. Upping the ante: recent advances in direct reprogramming. Mol Ther. 2009; 17(6): 947-53. 
[84] Hu, B.Y., J.P. Weick, J. Yu, L.X. Ma, X.Q. Zhang, J.A. Thomson, and S.C. Zhang. Neural differentiation of human induced pluripotent stem cells follows developmental principles but with variable potency. Proc Natl Acad Sci U S A. 2010; 107(9): 4335-40.

[85] Koyanagi-Aoi, M., M. Ohnuki, K. Takahashi, K. Okita, H. Noma, Y. Sawamura, I. Teramoto, M. Narita, Y. Sato, T. Ichisaka, N. Amano, A. Watanabe, A. Morizane, Y. Yamada, T. Sato, J. Takahashi, and S. Yamanaka. Differentiation-defective phenotypes revealed by large-scale analyses of human pluripotent stem cells. Proc Natl Acad Sci U S A. 2013; 110(51): 20569-74.

[86] O'Brien, C. and A.L. Laslett. Suspended in culture--human pluripotent cells for scalable technologies. Stem Cell Res. 2012; 9(2): 167-70.

[87] Fang, R., K. Liu, Y. Zhao, H. Li, D. Zhu, Y. Du, C. Xiang, X. Li, H. Liu, Z. Miao, X. Zhang, Y. Shi, W. Yang, J. Xu, and H. Deng. Generation of naive induced pluripotent stem cells from rhesus monkey fibroblasts. Cell Stem Cell. 2014; 15(4): 488-96.

[88] Caiazzo, M., M.T. Dell'Anno, E. Dvoretskova, D. Lazarevic, S. Taverna, D. Leo, T.D. Sotnikova, A. Menegon, P. Roncaglia, G. Colciago, G. Russo, P. Carninci, G. Pezzoli, R.R. Gainetdinov, S. Gustincich, A. Dityatev, and V. Broccoli. Direct generation of functional dopaminergic neurons from mouse and human fibroblasts. Nature. 2011; 476(7359): 224-7.

[89] Kim, H.S., J. Kim, Y. Jo, D. Jeon, and Y.S. Cho. Direct lineage reprogramming of mouse fibroblasts to functional midbrain dopaminergic neuronal progenitors. Stem Cell Res. 2014; 12(1): 60-8.

[90] Wang, Q., X. Xu, J. Li, J. Liu, H. Gu, R. Zhang, J. Chen, Y. Kuang, J. Fei, C. Jiang, P. Wang, D. Pei, S. Ding, and X. Xie. Lithium, an anti-psychotic drug, greatly enhances the generation of induced pluripotent stem cells. Cell Res. 2011; 21(10): 1424-35.

[91] Aasen, T., A. Raya, M.J. Barrero, E. Garreta, A. Consiglio, F. Gonzalez, R. Vassena, J. Bilic, V. Pekarik, G. Tiscornia, M. Edel, S. Boue, and J.C. Izpisua Belmonte. Efficient and rapid generation of induced pluripotent stem cells from human keratinocytes. Nat Biotechnol. 2008; 26(11): 1276-84.

[92] Lister, R., M. Pelizzola, Y.S. Kida, R.D. Hawkins, J.R. Nery, G. Hon, J. AntosiewiczBourget, R. O'Malley, R. Castanon, S. Klugman, M. Downes, R. Yu, R. Stewart, B. Ren, J.A. Thomson, R.M. Evans, and J.R. Ecker. Hotspots of aberrant epigenomic reprogramming in human induced pluripotent stem cells. Nature. 2011; 471(7336): 68-73.

[93] Hou, P., Y. Li, X. Zhang, C. Liu, J. Guan, H. Li, T. Zhao, J. Ye, W. Yang, K. Liu, J. Ge, J. $\mathrm{Xu}, \mathrm{Q}$. Zhang, Y. Zhao, and H. Deng. Pluripotent stem cells induced from mouse somatic cells by small-molecule compounds. Science. 2013; 341(6146): 651-4.

[94] Laurent, L.C., I. Ulitsky, I. Slavin, H. Tran, A. Schork, R. Morey, C. Lynch, J.V. Harness, S. Lee, M.J. Barrero, S. Ku, M. Martynova, R. Semechkin, V. Galat, J. Gottesfeld, J.C. Izpisua Belmonte, C. Murry, H.S. Keirstead, H.S. Park, U. Schmidt, A.L. Laslett, F.J. Muller, C.M. Nievergelt, R. Shamir, and J.F. Loring. Dynamic changes in the copy 
number of pluripotency and cell proliferation genes in human ESCs and iPSCs during reprogramming and time in culture. Cell Stem Cell. 2011; 8(1): 106-18.

[95] Soldner, F., J. Laganiere, A.W. Cheng, D. Hockemeyer, Q. Gao, R. Alagappan, V. Khurana, L.I. Golbe, R.H. Myers, S. Lindquist, L. Zhang, D. Guschin, L.K. Fong, B.J. Vu, X. Meng, F.D. Urnov, E.J. Rebar, P.D. Gregory, H.S. Zhang, and R. Jaenisch. Generation of isogenic pluripotent stem cells differing exclusively at two early onset Parkinson point mutations. Cell. 2011; 146(2): 318-31.

[96] Nakagawa, M., Y. Taniguchi, S. Senda, N. Takizawa, T. Ichisaka, K. Asano, A. Morizane, D. Doi, J. Takahashi, M. Nishizawa, Y. Yoshida, T. Toyoda, K. Osafune, K. Sekiguchi, and S. Yamanaka. A novel efficient feeder-free culture system for the derivation of human induced pluripotent stem cells. Sci Rep. 2014; 4: 3594. 
